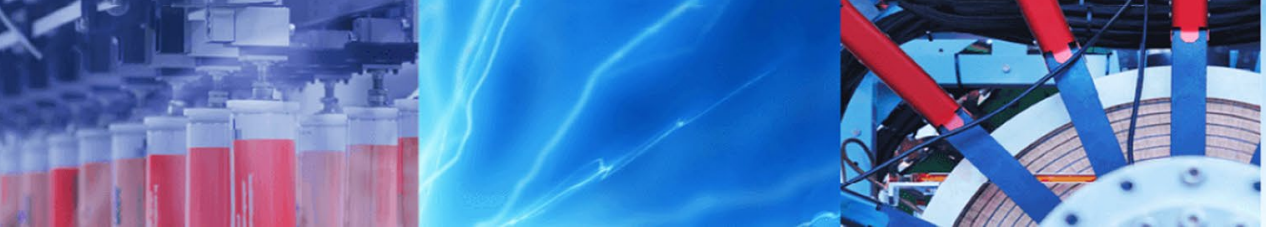

Research Article

\title{
Using infrared spectrum analyses to predict tensile strength of fibres in a group of closely related plant species: case of Mascarenes Pandanus spp.
}

\author{
Barisoa Harijaona Rafidison ${ }^{1}$ (1) $\cdot$ Hareenanden Ramasawmy ${ }^{1}$ [D $\cdot$ Jaykumar Chummun ${ }^{1}$. \\ F. Benjamin Vincent Florens ${ }^{2}$ (D)
}

Received: 31 March 2020 / Accepted: 12 October 2020 / Published online: 29 October 2020

(c) Springer Nature Switzerland AG 2020

\begin{abstract}
Replacing synthetic fibres with natural ones is key for clean and sustainable manufacturing. Natural fibres require characterization to investigate their usefulness. However, current testing methodologies require a large sample size due to the strong variation of tensile strength (TS) among the fibre of the same plant species. The development of a simpler test method to predict fibre TS would help in the selection of the most appropriate plant species with desirable TS values while performing fewer tests; thus saving on time and cost. FT-IR results that determine fibre crystallinity through specific IR absorbance peak ratios may serve to predict the fibre TS. In this study, we tested the relationship between fibre TS and cellulose crystallinity for seven different species of Pandanus spp. Thus, empirical mathematical relationships between the fibre TS value and indices obtained by three specific IR absorbance peaks ratios, namely the total crystallinity index, lateral order index, and hydrogen bond index have been established with a good correlation coefficient $(96,98$, and $95 \%$, respectively).
\end{abstract}

Keywords Crystalline cellulose $\cdot$ Infrared peak ratio $\cdot$ Natural fibres $\cdot$ Prediction · Tensile strength

\section{Introduction}

The bio-composite research field has grown rapidly in recent years, driven by the advantages that these materials hold over synthetic fibre composites, namely, their low environmental impact, low cost, their abundance, relatively high specific strength, and their potential use across a wide range of applications. Nature abounds with diverse fibre plants likely to be used as reinforcement in bio-composite materials. However, it is difficult to generalize the mechanical and physicochemical properties of natural fibres, because they vary greatly between species. This calls for a need to perform an array of tests in order to characterize the natural fibre in order to reach a decision as to whether the fibre can be a potential reinforcing material in composites. With these above-mentioned benefits, natural fibres-reinforced polymer composite (with fibres from Jute, Hemp, Kenaf, Oil-palm, or Bamboo) have been used in different automotive applications (rear storage shelf/panel, door panels, pillar cover, head-linear panel, seat back, spare tire-lining, cargo area floor mat, noise insulation panel, etc.), structural components, packing, and construction (building panels, window and door frame, bricks, panels, siding, fencing, roofing, decking, railing system, etc.).

The fibre tensile strength (TS) is a critical parameter in defining the choice of material for the fibre reinforcement. However, its value depends on several parameters

Barisoa Harijaona Rafidison, barisoa.rafidison@umail.uom.ac.mu | ${ }^{1}$ Department of Mechanical and Production, University of Mauritius, Reduit, Mauritius. ${ }^{2}$ Tropical Island Biodiversity, Ecology and Conservation Pole of Research, Faculty of Science, University of Mauritius, Reduit, Mauritius. 
such as microfibril angle, the crystallinity level, the fibre cell arrangement, the fibre size (cross-sectional dimension) and shape (the fibre length playing an important role in the composite strength rather than in the fibre TS). Additionally, there are settings such as gauge length, strain rate, gripping mechanism, load cell resolution, actuator precision, which can affect the value of the fibre TS. This explains the large discrepancies among values reported for natural fibre TS in the literature. The fibre TS range values given by literature present a significant variation: Roselle (170-350 MPa), Banana (180-430 MPa) [1]; Flax (345-2000 MPa), Ramie (400-1000 MPa), and Kenaf (240-930 MPa) [2]. Likewise, considerable variations are observed for the values given as mean and standard deviation (SD): Hemp (937 $\pm 975 \mathrm{MPa})$, Flax (1255 $\pm 1086 \mathrm{MPa})$ and Kenaf (284 $\pm 330 \mathrm{MPa})$ [3].

The large variation in the reported TS values for different natural fibres led researchers to choose a large number of tensile tests to have more accurate results. The choice of the sample size for the tensile test is arbitrary, because there is no standard that defines the number of tests to be employed. For instance, [4] performed 113 unit fibre tensile tests while [5] and [6] performed 150 and at least 50 tensile tests, respectively; thereby giving a relatively low coefficient of variation (around 0.5). Although the choice of a large number of tests reduces the coefficient of variation, researchers are often confronted with time and resource constraints.

On the other hand, techniques such as X-ray diffraction, differential scanning calorimetry (DSC), thermogravimetric analysis (TGA), Fourier transform infrared spectroscopy (FT-IR), and scanning electron microscopy (SEM) [7] can be, respectively, used to characterize crystallinity, thermal stability, proportions and presence of each chemical component, and morphology of natural fibres. Thus, researchers have attempted to find a possible correlation between the results given by the above-mentioned tests and the mechanical property of the natural fibres. A characterization of the fibre TS and crystallinity index of six cultivars of different pineapple varieties was carried out [8]. The authors noted that the high degree of cellulose crystalline index influence the fibre mechanical properties and demonstrated that there are intrinsic variabilities among the fibres from a pineapple leaf fibre variety. Some authors have determined the fibre crystallinity by calculating indexes based on the ratio of the absorbance peaks of the fibre infrared spectrum [9-12].

The fibre TS is proportional to the degree of crystalline cellulose and depends on the fibre chemical composition which varies greatly from one species to another. However, the relationship between these crystallinity indexes based on the ratio of the absorbance IR peaks and the fibre TS has not yet been investigated. Proposing a mathematical correlation between the results of various methods of fibre characterization and the tensile test value may serve as a useful and simple surrogate to predict the fibre TS.

The current work focuses on the computation of three indexes namely total crystallinity index $(\mathrm{TCl})$, lateral order index (LOI), and hydrogen bond index ( $\mathrm{HBI})$ to predict the fibre TS using seven different species of Mascarene screwpines Pandanus spp. having contrasting ecologies. The selection of these species has been based on several parameters covering ecological contrasts (e.g. species of drier versus wetter region; and species of sunlit versus shady places). An empirical equation linking the TS to each of these three indexes has been established. The possibility of prediction of fibre TS by the TGA/DTG results are presented.

\section{Materials and methods}

\subsection{Materials}

Six Pandanus species that are endemic to Mauritius and one endemic to the Mascarene Islands, namely: P. eydouxia, P. iceryi, P. macrostigma, P. rigidifolius, P. sphaeroideus, $P$. vandermeeschii and $P$. utilis, respectively, were selected for this study (by using several criteria such as abundance, accessibility, ease of growth and reproduction). All green leaves samples ( 15 leaves per species) were selected from plants cultivated in Curepipe, Mauritius (annual rainfall of $2000 \mathrm{~mm}$, centrally located at about $560 \mathrm{~m}$ elevation) except for $P$. rigidifolius and $P$. eydouxia, which were collected at around $700 \mathrm{~m}$ elevation. Total leaves for experiment was 105 leaves from 7 species.

\subsection{Extraction, reconditioning and tensile test}

The 105 green leaves were fed successively into a decorticator (Phoenix-India) to remove the cuticle, the epidermal layer and to extract the fibres (the remaining organic material resulting from decortication process has been discarded), and then washed with tap water prior to drying in an oven at $60^{\circ} \mathrm{C}$ for $24 \mathrm{~h}$. Tensile tests were performed on 50 single fibres for each species (30 thick and 20 thin fibres) according to the standard ASTM C155703 using a Testometric M500-50AT (Testometric Co. Ltd., United Kingdom) equipped with a $10 \mathrm{kgf}$ load cell and a gauge length of $25.4 \mathrm{~mm}$. During the extraction process, two types of fibres (thin and thick) were obtained. Thick fibres contained the main lumens of each fibre while the thin fibres seemed detached from the thick ones [13]. Three-sigma method was used to set the upper and lower control limits of the TS results in order to ensure results reliability and eliminate outliers (excessively high or low 
values outside the two horizontal lines $\pm 3 \mathrm{SD}$ ) that would significantly affect the average. The section measurement was performed according to the method used by Rafidison et al. [13], which consisted of measuring six marks print of the fibre cross section area made on plasticine at room temperature. The images were captured using a DigiMicro 5 MPix Microscope (Dnt-Germany) digital magnification $300 \times$ equipped with image acquisition software. The fibre imprints were measured by the imaging technique using the image J software (cross-platform, free and open-source software developed by the National Institutes of Health of United States). Only the minimum value (Table 1) of the six imprints was taken with a view to avoiding errors caused by small lateral movements during the implementation of the imprints.

\subsection{Probabilistic model of Weibull}

Because of its reliability, several authors have used the Weibull model to illustrate the distribution of the fibre TS. The Weibull method was used to determine the reliability of the tensile tests as well as the parameter of dispersion of the results and the homogeneity of the samples. According to this method, the probability of rupture $P_{\mathrm{f}}$ of a material of volume $V$ subjected to a uniform distribution of tensile stress $\sigma$ is given by the equation:

$P_{f}=1-\exp \left\{-V\left[\frac{\sigma}{\sigma_{0}}\right]^{m}\right\}$

$\sigma_{0}$ normalization factor without physical significance; $m$ factor describing both the inhomogeneity of the sizes of the defects and the degree of dispersion called "Weibull module".
The solution passes through the assignment to a level of constraints ranked in increasing order from 1 to $N$ at rank $i$ of a probability of rupture $P_{f}$ function of this rank thanks to the estimator given by the following expression:

$P_{f}=\frac{i}{N+1}$

The linearization of Eq. (1) of the probability of rupture makes it possible to determine the parameter of Weibull using:

$\ln \left\{\ln \left[1 /\left(1-P_{f}\right)\right]\right\}=m \cdot \ln \sigma-m \cdot \ln \sigma_{0}+\ln V$

The graphical representation of $\ln \left\{\ln \left[1 /\left(1-P_{\mathrm{f}}\right)\right]\right\}$ as a function of $\ln \sigma$ is a line of slope $m$.

\subsection{Fourier transform infrared (FT-IR) spectroscopy}

The objective of the FT-IR analysis is to estimate the cellulose crystallinity of the fibre as well as to qualitatively assess the main components of the fibre (cellulose, hemicellulose and lignin). FT-IR tests were carried out for each sample [a bundle of chopped fibre of about $0.1 \mathrm{~g}$ taken randomly from the extracted fibre of the 15 leaves of each species (Fig. 2a)] using a Bruker single bounce ATR-FT-IR spectrometer (Bruker ALPHA-Germany), equipped with OPUS software (Bruker -Germany).

A preliminary set of seven independent FT-IR tests were carried out to evaluate the relative error on the peak height which could occur, and this revealed an error of $2 \%$. Subsequently, three tests for each species were carried out ( 21 tests in total for the seven species), given that a test is the average of 25 scans with a resolution of $4 \mathrm{~cm}^{-1}$. The raw fibres were placed in a sterilized sample

Table 1 Tensile strength of the seven-Pandanus species (50 samples for each species) -load, cross section area (CSA) and tensile strength (TS)

\begin{tabular}{|c|c|c|c|c|c|c|}
\hline Species & Eydouxia & Rigidi-folius & Sphaero-ïdeus & Vander-meechii & Macr-ostigma & Utilis \\
\hline \multicolumn{7}{|l|}{ Load [N] } \\
\hline mean & 4.87 & 3.62 & 7.68 & 2.67 & 7.05 & 9.2 \\
\hline S.D & 2.75 & 1.81 & 3.69 & 0.8 & 3.87 & 3.1 \\
\hline \multicolumn{7}{|c|}{$\mathrm{CSA}\left[\mathrm{mm}^{2}\right]$} \\
\hline mean & 0.07 & 0.05 & 0.11 & 0.02 & 0.12 & 0.07 \\
\hline S.D & 0.05 & 0.03 & 0.08 & 0.01 & 0.1 & 0.03 \\
\hline \multicolumn{7}{|c|}{ TS* [MPa] } \\
\hline mean & 93.1 & 103.2 & 105.5 & 125.6 & 134.7 & 152.5 \\
\hline S.D & 70.9 & 64.6 & 91.4 & 53.3 & 118.6 & 84.1 \\
\hline
\end{tabular}

* Value of the mean of the 50 TSs which is different from the ratio of the means of 50 forces at break and CSAs. This allows to have a more accurate value since each of the 50 values of TS of each unit fibre has been calculated from its breaking force and its CSA 
holder then background measurement was evaluated as a reference standard before each test. The fibres to be analysed were placed under the probe [IR beam transmitter -receiver), clamped firmly and analysed by the spectrometer (Fig. 2a, b)]. The aim was to determine the lateral order index (LOI) [10]. This parameter was then obtained by the $1423 / 897 \mathrm{~cm}^{-1}$ height absorbance ratios. According to literature, the $897 \mathrm{~cm}^{-1}$ band is associated with amorphous cellulose $[14,15]$, so a higher intensity in this band indicates a higher amorphous content. Generally, a decrease in the LOI value indicates the drop in crystallinity $[14,15]$. Likewise, the $1370 / 2920 \mathrm{~cm}^{-1}$ ratio called total crystalline index $(\mathrm{TCl})$ was proportional to the crystallinity degree of the fibre cellulose. Evaluation of the TCI referring to around $2900 \mathrm{~cm}^{-1}$ band may also be associated with hydro carbonate linear chain extractives [16]. Indeed, fibres with higher extractive content (water-soluble or toluene ethanol-soluble or ether-soluble extractives) show higher values in this specific band, decreasing the calculated total crystallinity value [10]. Thus, higher TCl does not necessarily indicate higher crystallinity, because the extractives can influence this parameter.

Finally, the hydrogen bond index ( $\mathrm{HBI}$ ) was calculated to study the variation of hydrogen bonding between certain hydroxyl groups in cellulose. Generally crystallinity decreases with increasing HBI value [15]. Indeed, the height of the two peaks accurately measured using the OPUS 0.7 software (Bruker-Massachusetts, United States) tool at 3330 and $1320 \mathrm{~cm}^{-1}$ were closely associated with the crystalline cellulose and intra-, inter-molecular regularity [17].

Indeed, natural cellulose includes crystalline and amorphous regions. Cellulose content and cellulose crystallinity are two critical microstructural parameters that affect the fibre tensile properties such as TS, Young's modulus, elongation at break and plastic shrinkage. Given that polymers (including natural fibre) are materials, in which the covalent bond (very strong Van der Waals type bond linking the molecular chains) dominates; the rate of this type of bond is quantified by the crystallinity; therefore, its high value reduces the degree of freedom for the molecular chains to move, thus ensuring the fibre strength.

For the results validation, Dracaena floribunda and $D$. concinna leaf fibres, were extracted dried and tested in the same way as the Pandanus fibres. Tensile test and FT-IR analysis were conducted to obtain the TS and the LOI.

Dracaena floribunda and $D$. concinna were used to validate the result due to the fact that the authors of this present manuscript have the TS and FT-IR results of these two types of fibres measured under the same conditions (equipment and setting) used in this study. In addition, both plants genera (Pandanus and Dracaena) although belonging to different families (Pandanaceae and Asparagaceae, respectively) are monocotyledons of comparable sizes and were harvested in the same place. Finally, the fibres used come from their relatively similarshaped and sized leaves.

\subsection{Thermogravimetric analysis (TGA/DTG)}

TGA/DTG analysis was carried out using a NETZSCH TG 209F3A-0254-L (NETZSCH-Germany) $\left(25-1000{ }^{\circ} \mathrm{C}\right.$ at a heating rate of $10.0^{\circ} \mathrm{C} / \mathrm{min}$, one sample of mass of $7.29 \mathrm{mg}$ (mixed fibre from the 15 leaves), under $\mathrm{N}_{2}$ atmosphere, correction mass range of $820-2000 \mathrm{mg}$ and $\mathrm{Al}_{2} \mathrm{O}_{3}$ crucible) for each species. The result was processed with NETZSCH Proteus software (Germany). Its purpose is to estimate the cellulose amount through the thermal degradation (TGA) and the temperature exchange peak (DTG) curves (to detect the temperature corresponding to the maximum degradation, as well as the inflexion points marking a change in atomic structure), thus supporting the results of the estimation of the fibre crystallinity through the IR indices. Based on the assumption that a high percentage of cellulose should indicate a high probability of having cellulose crystalline, therefore having a high fibre TS.

\section{Results and discussion}

\subsection{Tensile test}

The TS of the 50 single fibres for each of the seven Pandanus species are summarized in Table 1. In order to take into account the interaction of load and cross section area (CSA), the average of 50 TS results was used (Table 1), which is different from the ratio of the average load and average CSA. According to the tensile test results, the seven Pandanus species can be classified in descending order of TS as follows: P. eydouxia, P. iceryi, P. macrostigma, $P$. rigidifolius, $P$. sphaeroideus, $P$. utilis, and $P$. vandermeeschii.

The difference between the lowest and the strongest tensile values reaches $68.4 \%$, which explains that the fibre TS of natural fibre vary significantly between species. In the case of Pandanus, it has been observed that fibres from relatively short mature leaves (P. rigidifolius and $P$. vandermeeschii) exhibit lower TS when compared to the long ones (P. macrostigma, P. iceryi and $P$. utilis). Furthermore, fibres from species which have narrow mature leaves ( $P$. rigidifolius, $P$. vandermeeschii, $P$. sphaeroideus and P. eydouxia) have lower TS.

The two types of fibres (thin and thick fibre) on the $P$. utilis presented by Rafidison et al. [13] have been observed in all other species studied in this manuscript (Fig. 1a). As expected, after extraction, two types of fibres were again obtained. The effect of repeated stress during the 


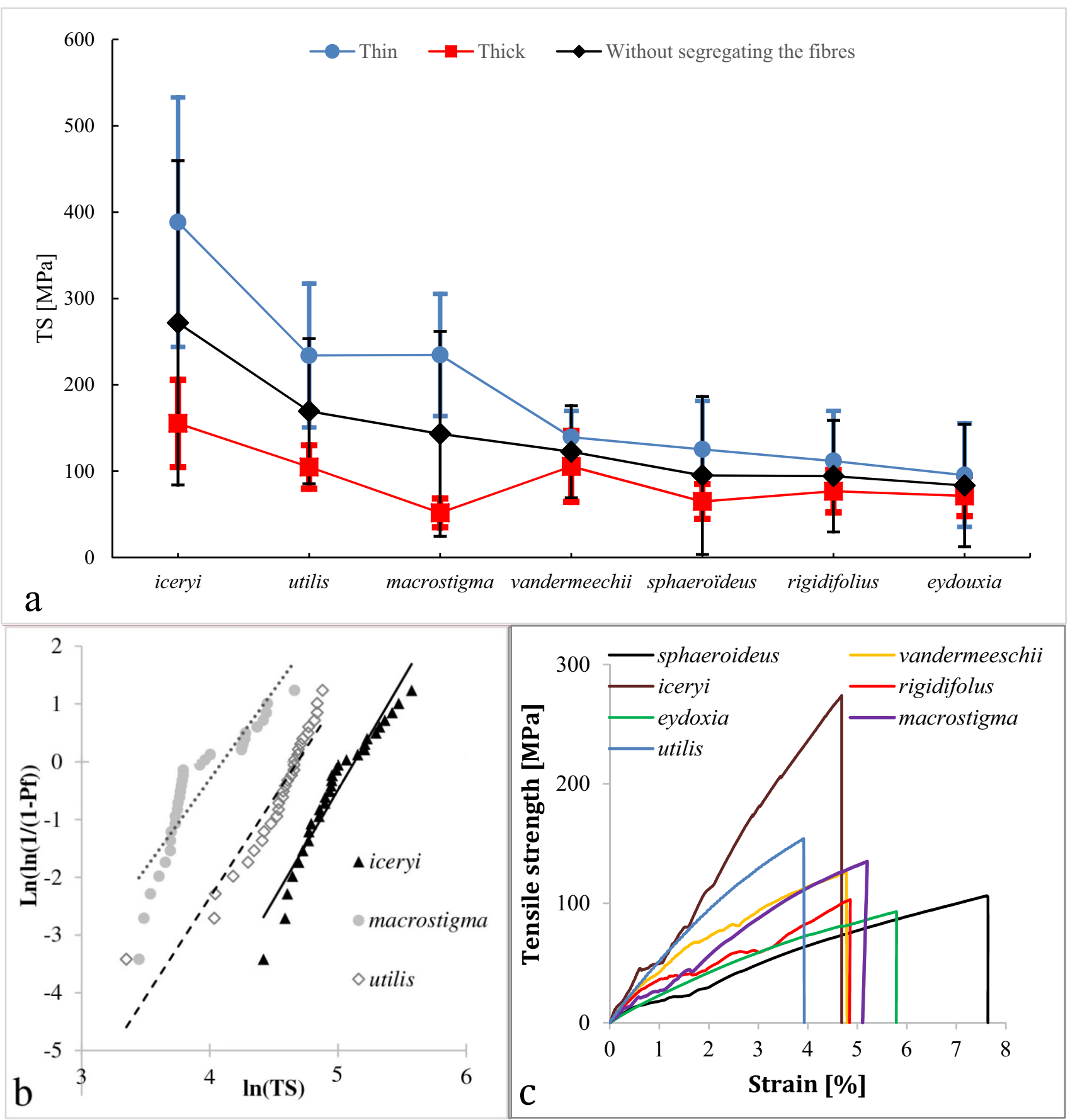

Fig. 1 a Tensile strength of thin, thick and unsegregating fibre, b Graphical representation of the linear probability equation (Weibull) for three species. c Tensile strength-strain curve of sphaeroideus and vandermeechii

extraction process breaks the weak bond between the elementary fibres, thus generating individual thin fibre with smaller CSA. The absorbance peaks show that, qualitatively both types have the same chemical functional groups, therefore the same components; what differentiates them is the structure. Indeed, the thick fibre is much less resistant than the thin one since it contains the main lumen and presents more voids. 


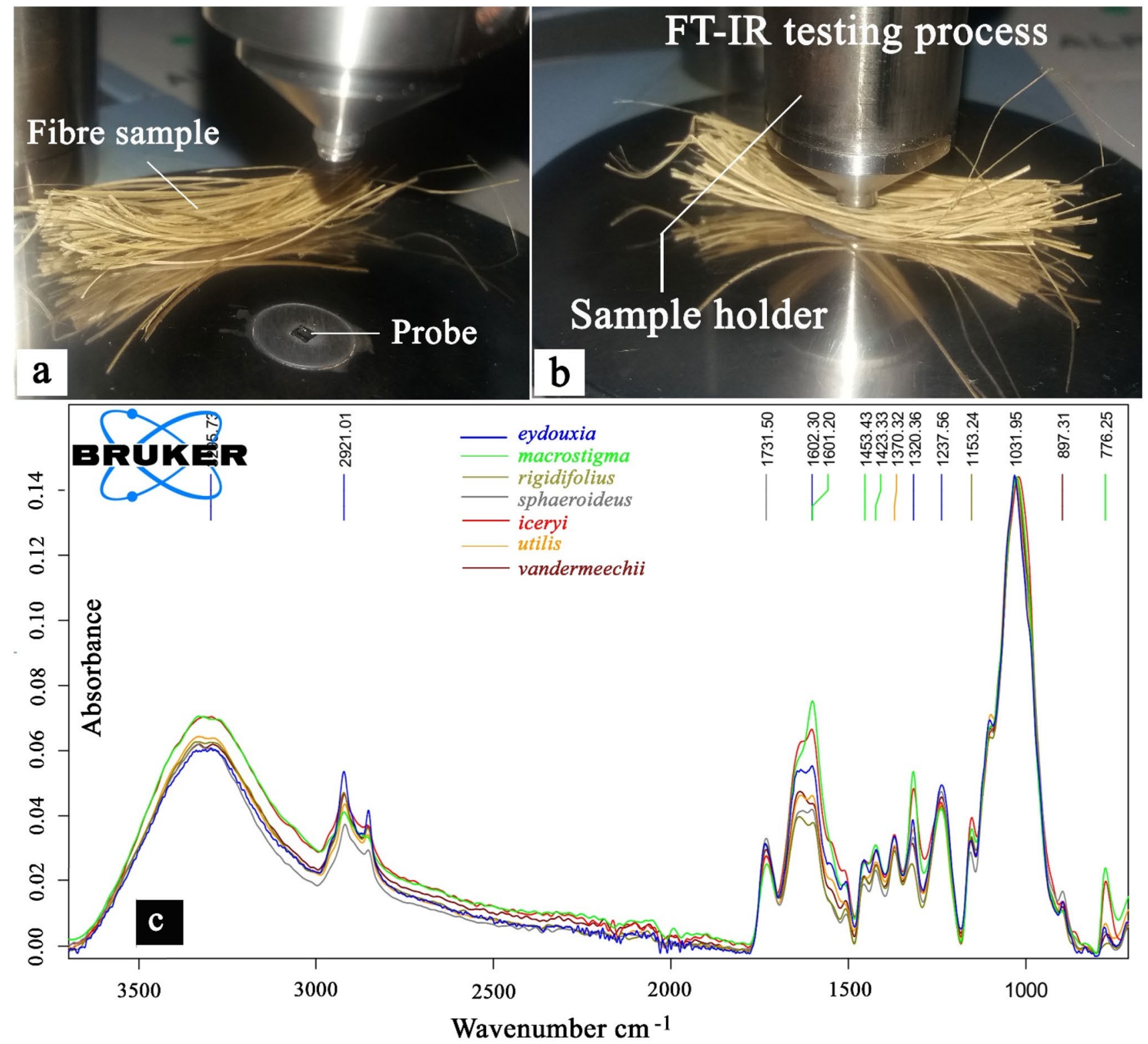

Fig. 2 a FT-IR test description. b FT-IR testing process. c Absorbance spectra IR of seven Pandanus species

In order to have more reliable results, a filter using three-sigma limits was performed. The outliers have not been used for further compilation and analysis. Generally, three test results of the 50 samples were outliers, except for P. macrostigma, which exhibited a significant scattering of the values of the fibre's cross-sectional area.

The average CSA of the seven Pandanus species fibres is $0.07 \pm 0.03 \mathrm{~mm}^{2}$. Pandanus macrostigma's cross-sectional area is $0.12 \pm 0.10 \mathrm{~mm}^{2}$ while the smallest area is recorded in $P$. vandermeeschii with $0.02 \pm 0.01 \mathrm{~mm}^{2}$. The significant variation of the CSA of $P$. macrostigma explains the large variation in TS of these fibres $(134.7 \pm 118.65 \mathrm{MPa})$.
While the average elongation of Pandanus species is $1.3 \pm 0.3 \mathrm{~mm}(5.1 \%), P$. sphaeroideus has a maximum elongation of $1.9 \pm 0.3 \mathrm{~mm}(7.5 \%)$ and $P$. vandermeeschii has a minimum elongation of $1.1 \pm 0.3 \mathrm{~mm}$ (4.3\%) (Fig. 1c). The average of thin fibre TS for all the seven species is $189.8 \pm 35.8 \mathrm{MPa}$ with a maximum of $388.3 \pm 144.5 \mathrm{MPa}$ for $P$. iceryi and a minimum of $95.4 \pm 59.9 \mathrm{MPa}$ for $P$. eydouxia. The difference between these two values is $75.4 \%$. The average TS for thick fibre for all the seven species is $90.0 \pm 12.3 \mathrm{MPa}$ (max: $155.2 \pm 50.6 \mathrm{MPa}$, min: $71.2 \pm 23.3 \mathrm{MPa}$ ). The variation of the TS for thick fibres is small compared to that of the thin ones and the percentage gap of these TS is $52.6 \%$. In order to validate the TS 
difference for thin and thick fibres, a comparative analysis of the IR spectrum has been carried out.

\subsection{Application of the Weibull model}

The graphical representation of the linear probability equation for the determination of the Weibull modulus is illustrated in Fig. $1 \mathrm{~b}$. For better clarity of the diagram, only three species are presented in Fig. 1b. It is observed that there is a dispersion of the experimental points around the linear regression line of the probability equation.

The average of the Weibull modulus value $(\mathrm{m})$ is 1.90 $\left(R^{2}=0.89\right)$, which is deemed to be very small. This value represents the strong inhomogeneity linked to the abovementioned various factors (fibre type, accumulation of measurement errors, intrinsic fibre defects). It should be noted that the Weibull modulus is an indicator of dispersion. The weaker it is, the more this dispersion is important. For the low values of the Weibull modulus (generally for $m<20$ ), the distribution of defects varies significantly from one sample to another, thus generating a strong dispersion of the breaking stresses within a group of fibres. The average of $m$ is small even by studying thin and thick fibres separately (2.91 and 3.44, respectively). The significant variation could be caused by the changing sample cross section. These combined different sources of errors generate a notable dispersion in the TS results.

\subsection{Fourier transform infrared (FT-IR) spectroscopy}

FT-IR analysis allows determining the specific IR peaks relating to the cellulose crystallinity of the fibre as well as the qualitative difference of the main constituent elements of the fibre such as cellulose (amorphous or crystalline), hemicellulose and lignin. These elements have atomic bonds proper to their respective structure and an IR peak obtained by FT-IR gives information on the existence of these bonds. Given that the cellulose crystallinity is an intrinsic property which affects fibre strength, the evaluation of this cellulose crystallinity would help in the determination of the fibre tensile strength.
The absorption bands for characteristic chemical groups of the lignocellulose Pandanus fibre can be observed in Fig. 2c. The untreated Pandanus fibre showed similar patterns with the dominant peaks observed at approximately $3324 \mathrm{~cm}^{-1}(\mathrm{O}-\mathrm{H}$ stretch), characteristic of the stretching vibration of the $-\mathrm{OH}$ bonds cellulose and hemicellulose, $2918 \mathrm{~cm}^{-1}$ stretching of $-\mathrm{CH}$ bonds of cellulose chains and hemicellulose, $2853 \mathrm{~cm}^{-1}$ stretching $-\mathrm{CH}_{2}$ bonds of cellulose and hemicellulose, $1732 \mathrm{~cm}^{-1}(\mathrm{C}=\mathrm{O}$ stretching) lignin, $1635 \mathrm{~cm}^{-1}$ shear vibration of the free water $\mathrm{OH}$ bond, $1603 \mathrm{~cm}^{-1}, 1627 \mathrm{~cm}-1$ and $1513 \mathrm{~cm}^{-1}$ (associated with the aromatic $\mathrm{C}=\mathrm{C}$ in plane symmetrical stretching vibration of aromatic ring present in lignin), $1422 \mathrm{~cm}^{-1}$ vibration of the carboxyl bond characteristic of pectin, $1245 \mathrm{~cm}^{-1}(\mathrm{O}-\mathrm{H}$ vibration of phenolic group), $1100 \mathrm{~cm}^{-1}$ (C-O-C stretching) cellulose, $1051 \mathrm{~cm}^{-1}\left(\mathrm{O}-\mathrm{H}\right.$ stretching), and $897 \mathrm{~cm}^{-1}$ ( $\beta$-glycosidic linkage) cellulose [11].

In this context, the aim is to analyse the specific IR peaks in order to extract information on the fibre crystallinity which affects the TS as explained in Sect. 2.4. The IR spectrum peaks used to determine crystallinity are 3332 , 2920, 1423, 1370, 1320, and $897 \mathrm{~cm}^{-1}$ [9, 21] (Fig. 2C). The $\mathrm{TCl}$ and $\mathrm{LOI}$ indices were used to evaluate the IR crystallinity ratio, and the $\mathrm{HBI}$ was used to evaluate the hydrogen bond intensity of cellulose (this ratio is closely related to the crystal system and the degree of intermolecular regularity, that is, crystallinity, as well as the amount of bound water) [19]. In the following section, the discussion focuses on crystalline-cellulose I and amorphous structure since the fibres have not undergone any chemical treatment $\left(\mathrm{NaOH}\right.$ or $\left.\mathrm{NH}_{3}\right)$.

The lateral order index (LOI) $[9,10]$ which is obtained from the IR pattern by the $1423 / 897$ height absorbance ratio was also determined. Since the peak at $1423 \mathrm{~cm}^{-1}$ is associated with the crystalline cellulose I while the $897 \mathrm{~cm}^{-1}$ peak is associated to the amorphous cellulose $[18,20]$, this ratio characterizes the crystallinity therefore the fibre TS. Before measuring the absorbance height, spectra were normalized from the maximum peak (occurring at $1030 \mathrm{~cm}^{-1}$ ) corresponding to $\mathrm{C}-\mathrm{O}$ and $\mathrm{C}-\mathrm{C}$; sketching in cellulose $\left(\mathrm{C}_{6}-\mathrm{H}_{2}-\mathrm{O}_{6}\right)$ [21]. Table 2 summarizes the
Table 2 Lateral order index (LOI), total crystallinity index (TCl) and hydrogen bonding index (HBI) of seven Pandanus species

\begin{tabular}{llll}
\hline Species & LOI $[-]\left(1423 / 897 \mathrm{~cm}^{-1}\right)$ & $\mathrm{TCl}[-]\left(1370 / 2920 \mathrm{~cm}^{-1}\right)$ & $\begin{array}{l}\mathrm{HBI}[-] \\
\left(3332 / 1320 \mathrm{~cm}^{-1}\right)\end{array}$ \\
\hline iceryi & 3.90 & 0.74 & 1.40 \\
macrostigma & 3.88 & 0.81 & 1.58 \\
utilis & 3.43 & 0.67 & 1.75 \\
vandermeechii & 2.93 & 0.67 & 1.91 \\
sphaeroïdeus & 2.93 & 0.63 & 2.14 \\
rigidifolius & 2.31 & 0.63 & 2.35 \\
eydouxia & 2.14 & 0.64 & 1.92 \\
\hline
\end{tabular}


Fig. 3 TS versus lateral order index (LOI), total crystallinity index $(\mathrm{TCl})$ and hydrogen bond index $(\mathrm{HBI})$

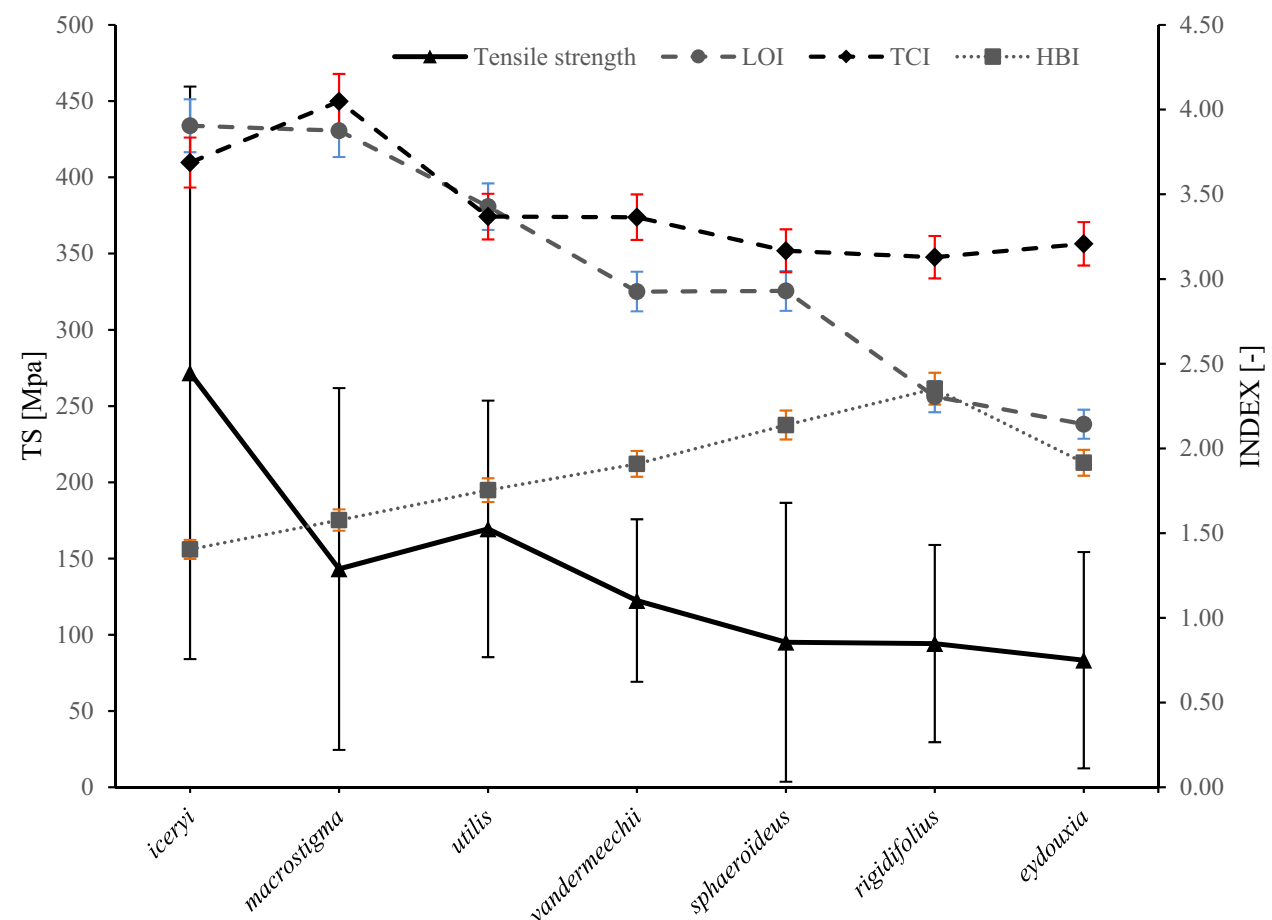

LOI of the seven Pandanus species. As shown in Fig. 3, the computed LOI value correlates very well with the tensile test value for each Pandanus species except for $P$. macrostigma, which has a lower TS than $P$. utilis despite having a higher value of LOI. The excessive variation in the TS value for $P$. macrostigma fibres is one reason, which may explain this discrepancy. Although the mean TS of $P$. utilis is $11.7 \%$ higher than that of $P$. macrostigma, the SD of $P$. utilis is $29.1 \%$ lower than that of $P$. macrostigma, i.e. the maximum value of $P$. macrostigma TS is larger than that of $P$. utilis. On the other hand, the gap of mean-TS of thin fibres between $P$. utilis and $P$. macrostigma is of only $0.25 \%$ but, the SD is 83.3 and $70.7 \mathrm{MPa}$, respectively. This could explain why the LOI value of $P$. macrostigma is higher than that of $P$. utilis.

Table 2 also shows the results of $\mathrm{TCl}$ and $\mathrm{HBI}$, the trends of the results corroborate with that of the TS as shown in Fig. 3. The TCl follows the same trend as the LOI. As expected, the $\mathrm{HBI}$ decreases (maximum relative variation of $12 \%$ ) with the increase in TS. In general, the results of the three indices show that the high TS fibres have higher $\mathrm{TCl}, \mathrm{LOI}$, and lower HBI.

LOI comparison of thin and thick fibres shows thick fibres to exhibit significant variation (thin fibres' LOI is $17.4 \%$ more than that of the thick one for P. macrostigma). This difference (which may be interpreted as a difference in crystallinity) corroborates with the values of TS mentioned in Sect. 2.6. It is important to note that it is possible to isolate the thin fibre from the thick one during the fibre extraction process but it is difficult to ensure that the latter fibre no longer contains any of the former one.

\subsection{Thermogravimetric analysis (TGA)}

Natural fibre is mainly composed of cellulose, hemicellulose and lignin. The temperature range of the thermal degradation is different for each of these components. Thus, the TGA analysis allows the detection of the presence and the estimated quantity of each component, whereas the DTG allows the analysis of the variations in heat energy exchanges which accompany the thermal degradation of the component.

The thermal degradation behaviour (TGA) curves of $P$. utilis, P. sphaeroideus, P. iceryi, P. rigidifolius, P. vandermeeschii and $P$. macrostigma fibres are shown in Fig. 4. In theory, higher thermal stability means higher crystallinity [22] therefore higher TS. As explained in Sect. 2.5, the aim of this part is to support the FT-IR results through estimating the cellulose amount given by TGA/DTG curves.

To estimate the percentage of each element (cellulose, hemicellulose, lignin and pectin), the percentage of the mass loss has been recalculated without accounting for water evaporation. In addition, the mass loss from stage III was counted as mass loss of stage III (Table 3). The percentage analysis of the elements presented in this study is limited on an approximation based in the shape changes of the TG and DTG curves. Indeed, chemical composition should be determined by successive removal of 


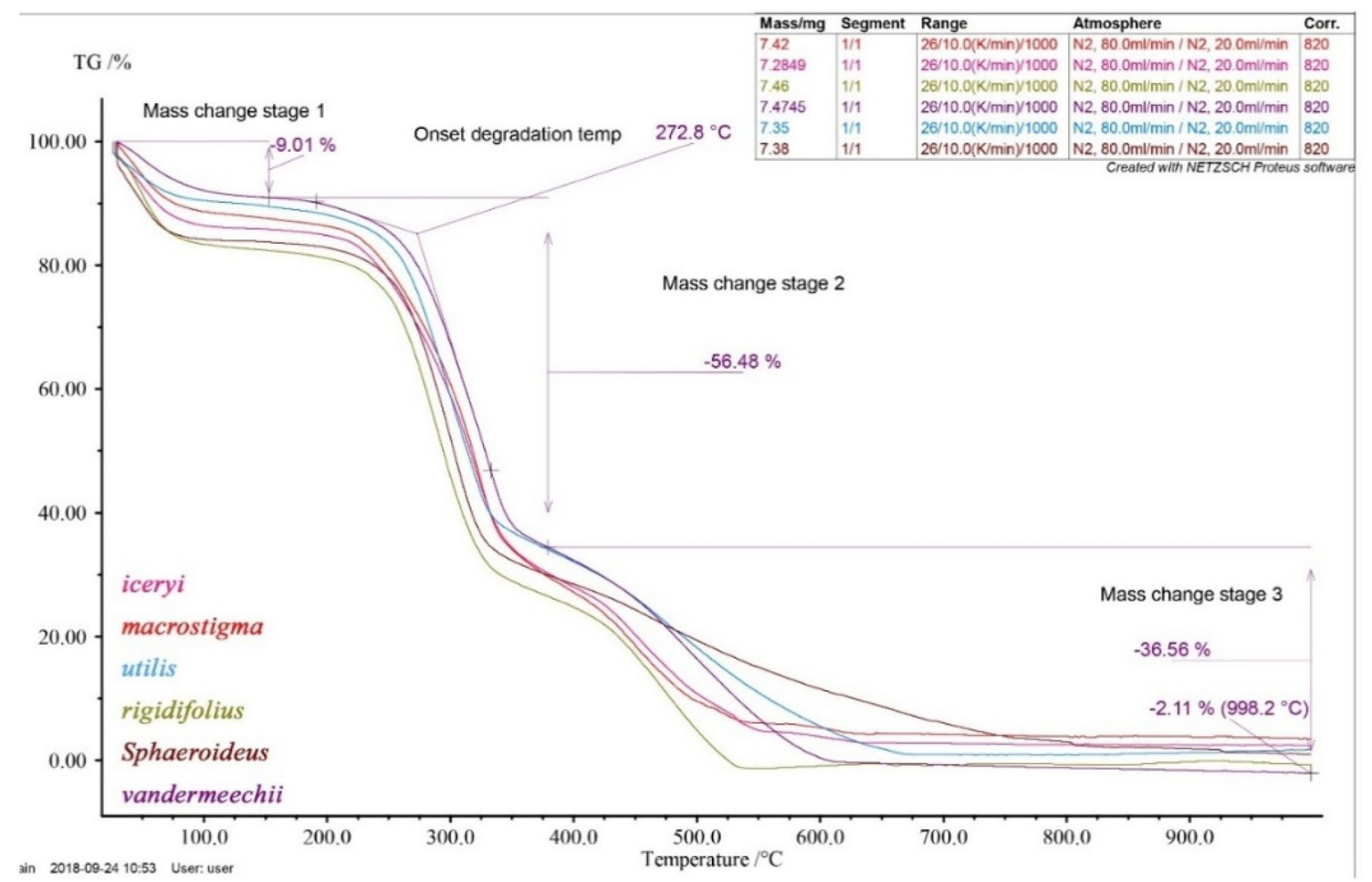

Fig. 4 Thermal degradation of six Pandanus species

Table 3 Percentage of mass loss without moisture (Stage II: percentage of cellulose)

\begin{tabular}{lrllllr}
\hline Stage & Iceryi & Macrostigma & Rigidifolius & Sphaerö̈deus & Vandermeechii & Utilis \\
\hline II & 67.03 & 67.41 & 66.56 & 65.23 & 61.16 & 62.25 \\
III & 30.23 & 28.69 & 32.65 & 33.63 & 33.61 & 36.76 \\
Residue (ash) & 2.75 & 3.91 & 0.80 & 1.15 & 5.23 & 0.99 \\
\hline
\end{tabular}
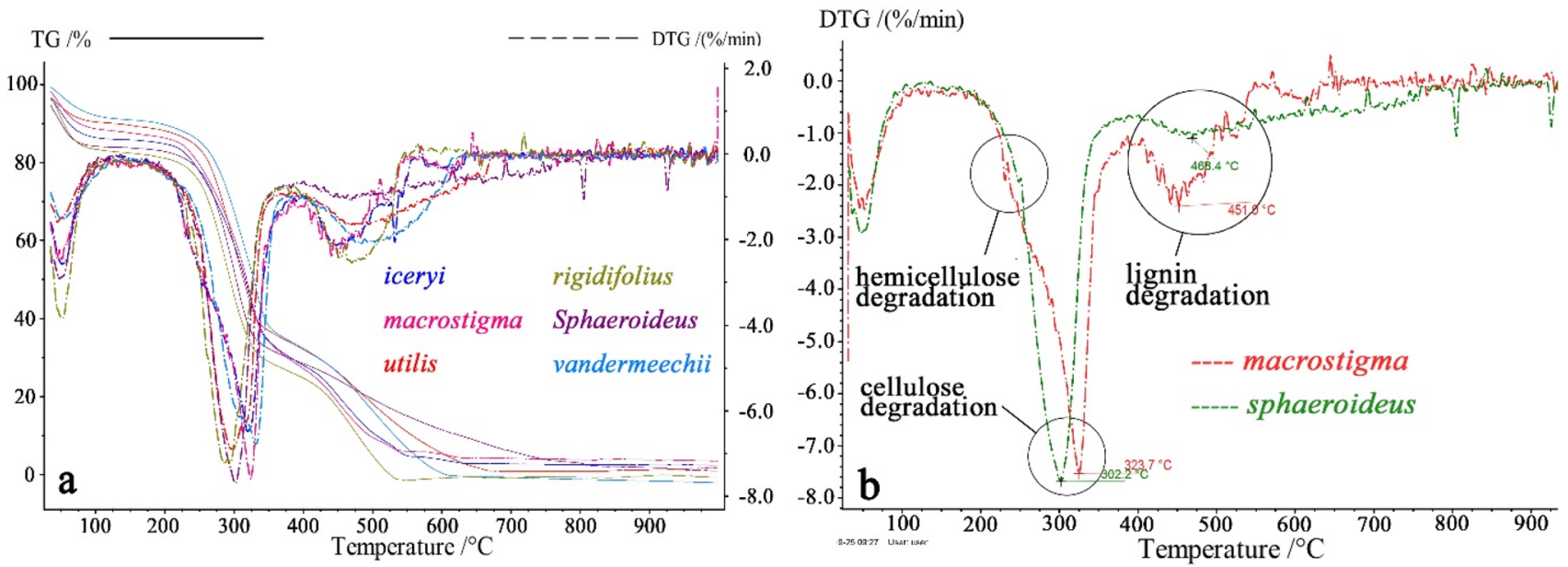

Fig. 5 a DTG and TG of six Pandanus species, b DTG analysis of $P$. macrostigma and $P$. sphaeroideus fibre 
components to obtain values that are more accurate. Nevertheless, a trend consistent with the results of the FT-IR analysis has been observed.

Figure $5 \mathrm{~b}$ shows the two types of DTG curve patterns of Pandanus (P. macrostigma and P. sphaeroideus). These two species have been taken as an example because of the large gap of their TS and the notable difference in their thermal degradation curves. The degradation of hemicellulose is visible for both species $\left(230^{\circ} \mathrm{C}\right)$ followed by cellulose degradation. This degradation ends at $302.2^{\circ} \mathrm{C}$ for P. sphaeroideus and $323.7^{\circ} \mathrm{C}$ for P. macrostigma; this difference of $6.7 \%$ illustrates that there is more crystalline cellulose in the $P$. macrostigma than in the $P$. sphaeroideus (same for the $P$. vandermeeschii and $P$. rigidifolius). Unlike $P$. sphaeroideus, $P$. macrostigma cellulose degradation curve has a knee-point, which could be explained by the existence of a different cellulosic structure (Fig. 5a, b) (same observation is noted for P. iceryi and P. utilis).

As shown in Fig. $5 a$, b, the amount of hemicellulose is very low in all species; therefore its degradation merges with that of the cellulose in the TGA curve. Its presence is justified by the very low IR band at $2851 \mathrm{~cm}^{-1}$ (Fig. 2C.) and the DTG peak around $250^{\circ} \mathrm{C}$ (Fig. 5a). Indeed, each phase change in thermal degradation is marked by the presence of a inflexion point in TGA and a peak in DTG curves [23]. Then, the distance between the ordinates of two inflexion points in the TGA curve gives the relative percentage of each element (extractive, hemicellulose, cellulose and lignin).

The amount of hemicellulose in $P$. utilis seems very low compared to that of other species since its DTG curve is not present at a peak at around $250^{\circ} \mathrm{C}$, in addition, the IR band-height at $2851 \mathrm{~cm}^{-1}$ is almost zero. Thus, the kneepoint relating to cellulose appears at a higher temperature $\left(258.5^{\circ} \mathrm{C}\right)$ for $P$. utilis as compared to the other species. This could explain the low percentage of cellulose in $P$. utilis even if it has relatively high TS.

The values shown in Table 3 (percentage of cellulose in stage II) seem to be related to TS except for $P$. utilis (62.5\%) whose reason could be explained by the above paragraph. Generally, the IR indices and the relative percentage of cellulose given by the TGA/DTG have the same trend as the TS results. Thus, the results of thermal behaviour can support the hypothesis of the possibility of deducing the fibre TS through the calculation of the IR indices.

\subsection{Correlation of the results and validation}

Apart from the variations due to the accumulation of measurement error, the variation of the TS within a species comes from the variations of the lumens, the microvoids, and the possible defects. Practically, it is difficult, even impossible to have the sizes of the lumens and microvoids for each tested fibre. Thus, relatively many tests (50 in the present case) are needed to minimize this problem. Then, the values of TS given are apparent values, because they are deduced from the apparent cross section area (materials, lumen and voids).

Thus, (TS) $)_{\text {apparent }}=\alpha *(\mathrm{TS})_{\text {real }}, 0<\alpha<1$.

On the other hand, the FT-IR measurement gave results independently of the lumens and the voids since the variation between each measurement does not exceed $2 \%$ in a species. Indeed, the measurement gives information on the atomic bond existing in the fibre. Still, the mechanical properties of a given material, in particular the TS depend on the constituents of the materials. Thus, there is a relationship such that:

$(\mathrm{TS})_{\text {real }}=f\left(i_{\mathrm{IR}}\right)$.

$i_{\mathbb{R}}$ information given by IR spectra; According to the above hypotheses, the function $f$ exists; however its expression is completely unknown; Then, it is possible to have a correlation between (TS) apparent and $i_{I_{R}}$ such that:

$(\mathrm{TS})_{\text {apparent }}=\alpha * f\left(i_{\mathbb{R}}\right)=g\left(i_{\mathbb{R}}\right)$

The function $g\left(i_{\mathbb{R}}\right)$ can be determined since it is possible to determine apparent $(T S)_{\text {apparent }}$. Figure 6 shows the regression curves connecting the TS and the indexes $(\mathrm{LOI}, \mathrm{TCl}$ and $\mathrm{HBI}$ ). According to this figure, it is possible to predict the relative TS of a natural fibre from the three indices. In fact, the fibre TS depends closely on the cellulose crystallinity of the fibre. However, it is important to note that the measurement of TS is one method for determining the stronger fibre but that does not mean that it is effective. The determination of the Weibull modulus shows that the value given by the tensile test presents a significant dispersion.

After calculating the statistical reliability ( $F$ test) of the tensile results between two species, it has been shown that the variance between $P$. utilis and $P$. macrostigma are not significant $(F=0.512<F$ critical $=0.62)$, likewise for $P$. vandermeeschii and $P$. sphaeroideus $(F=0.339<F$ criti$\mathrm{cal}=0.622$ ). This could be the source of the discrepancy between the indices' values and the fibre TS of these two species.

The LOI of $P$. iceryi and $P$. macrostigma are nearly identical (3.90 and 3.88, respectively, corresponding to a difference of $0.76 \%$ ) while the gap between the TS after three sigma filter is significant (271.7 and $143.1 \mathrm{MPa}$, respectively, corresponding to $47.3 \%$ difference $\left.\left(F=2.5>F_{\text {critical }}=1.6\right)\right)$. Similarly, the estimated amount of cellulose given by the TGA (Table 3) of the two species is very close (67.03 and 

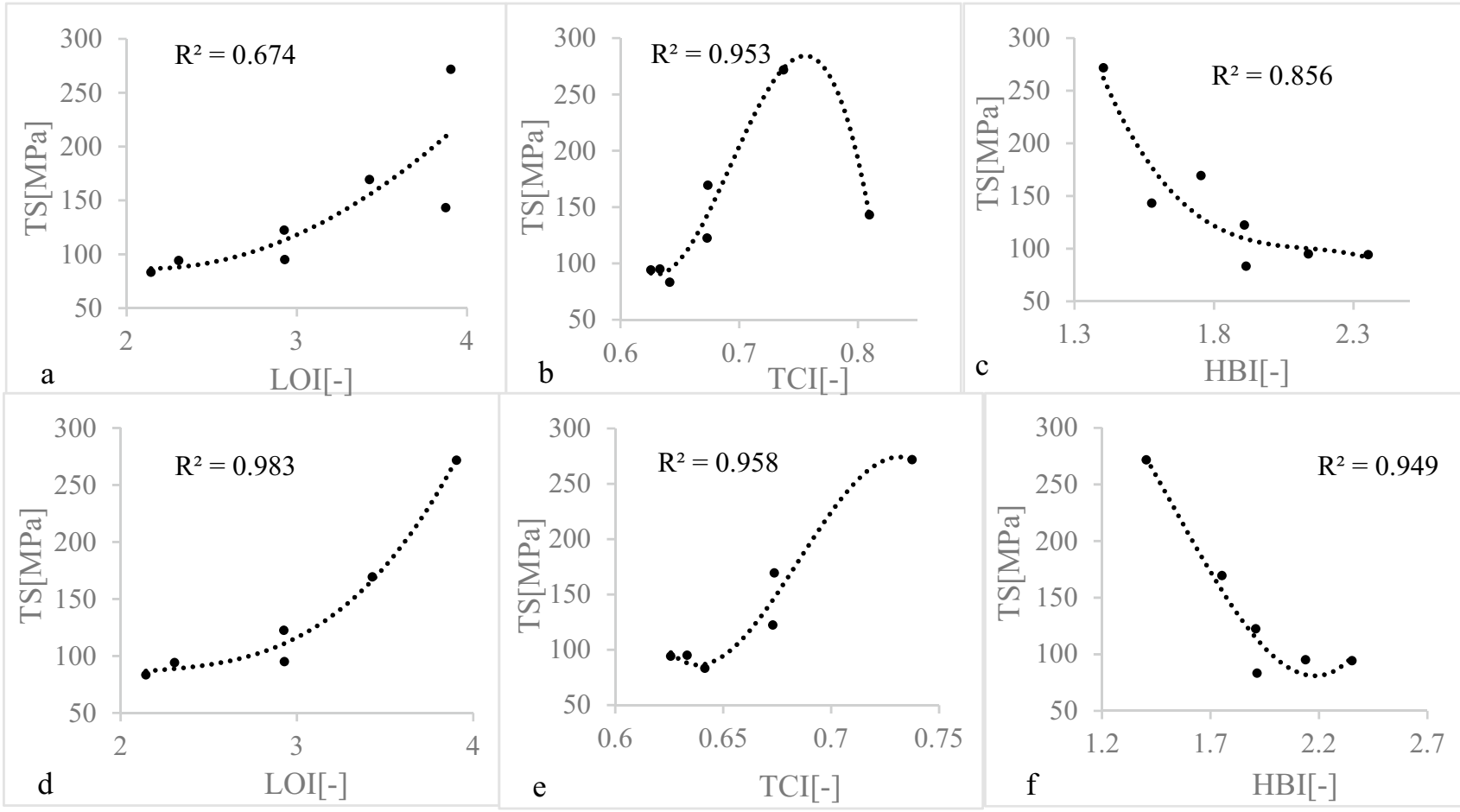

Fig. 6 a-c Third-order polynomial regression of Pandanus TS/(LOI, TCl and HBI) d-f Third-order polynomial regression of Pandanus (without P. macrostigma) $\mathrm{TS} /(\mathrm{LOI}, \mathrm{TCl}$ and $\mathrm{HBI})$

67.41 , respectively). This implies that a dominant parameter other than the cellulose crystallinity level is responsible for the difference in TS. It could be the structural difference of crystalline cellulose or the microfibril angle.

Figure $6 a-c$ show the empirical relationship between $\mathrm{TS} / \mathrm{LOI}, \mathrm{TCl}$ and $\mathrm{HBI}$, respectively. The $\mathrm{LOI}$ and the $\mathrm{HBI}$ are monotonic and the $\mathrm{HBI}$ correlates with TS $\left(\mathrm{R}^{2}=0.85\right)$ as compared to the other. Without the $\mathrm{TCl}$ value of $P$. macrostigma, the $\mathrm{TCl}$ regression will have a good correlation with the TS. In addition, the $\mathrm{R}^{2}$ of LOI is weak (0.67), because the curve of regression is influenced by the value of LOI of $P$. macrostigma. All of this is probably explained by the dispersing results between the thin and thick fibre already mentioned above. Figure $6 \mathrm{~d}-\mathrm{f}$ show the new regression of the curve without P. macrostigma and Eqs. 7, 8 and 9 give the relationship between TS and the three indexes based on the experimental data of this study.
Table 4 Confrontation of experimental and theoretical predictive results

\begin{tabular}{lllllr}
\hline & LOI & $\begin{array}{l}\text { Measured } \\
\text { TS (MPa) }\end{array}$ & SD & $\begin{array}{l}\text { Theoretical } \\
\text { TS (MPa) }\end{array}$ & Error \% \\
\hline D. floribunda & 2.2 & 186 & 43 & 191.4 & 2.82 \\
D. concinna & 1.55 & 144 & 54.6 & 168.8 & 14.69 \\
\hline
\end{tabular}

Since the TS values in the $y$-axis are the same for the indices, the index with the largest coefficient of variation should be more reliable than the others. Certainly, a weak variation could be generated by measurement errors. In the present case, the coefficient of variation $C_{v}$ (ratio of SD and mean value) of the $\mathrm{LOI}$ is $22 \%$ while those of the TCI and $\mathrm{HBI}$ are 9 and $16 \%$, respectively. For this reason, the LOI will be used for the results validation. In addition, the $\mathrm{HBI}$ should be used with more caution since the influence

$(\mathrm{LOI}): \mathrm{TS}=29.039(\mathrm{LOI})^{3}-184.15(\mathrm{LOI})^{2}+400(\mathrm{LOI})-210.53\left(R^{2}=0.98\right)$

$(\mathrm{TCl}): \mathrm{TS}=-462693(\mathrm{TCl})^{3}+950700(\mathrm{TCl})^{2}-648778(\mathrm{TCl})+146767\left(R^{2}=0.95\right)$

$(\mathrm{HBI}): \mathrm{TS}=264.46(\mathrm{HBI})^{3}-1207.10(\mathrm{HBI})^{2}+1491.10(\mathrm{HBI})-172.80\left(R^{2}=0.94\right)$ 

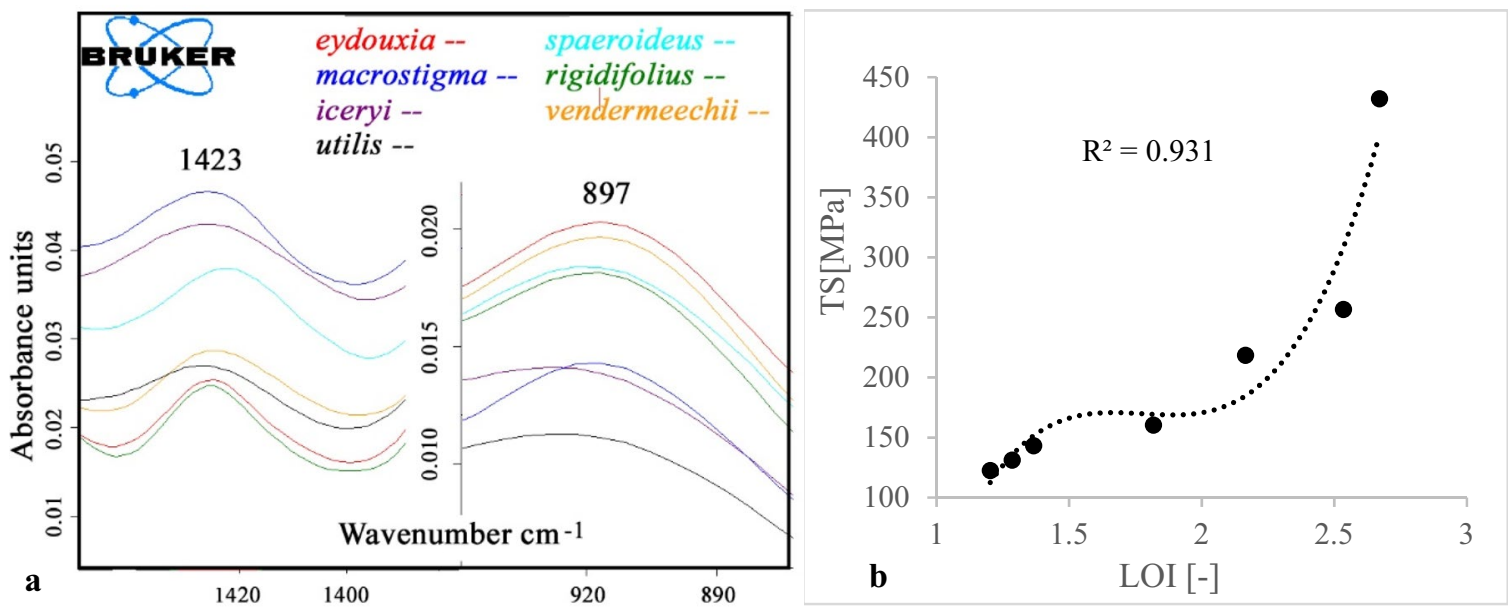

Fig. 7 a Spectra at 1420 and $897 \mathrm{~cm}^{-1}$ for the seven Pandanus species $\mathbf{b}$ Third-order polynomial regression of thin fibre Pandanus tensile strength (TS) vs/(lateral order index (LOI)

of other fibre components, such as extractives, hemicellulose and lignin associated with higher quantities of bound water, may contribute to false interpretation [10].

To validate the results, the LOI values of two leaf-fibres of two different species of the same genus (Dracaena floribund $a$ and $D$. concinna) were measured. The obtained values were introduced into Eq. 10 to determine their theoretical TS. These latter values have been compared with the experimental TS value of both species (Table 4). Unlike Pandanus, D. floribunda and D. concinna leaf fibres do not comprise two types of fibres (thin and thick). The cross section area and visual appearance of the fibres are similar to thin fibre Pandanus $\left(0.02 \mathrm{~mm}^{2}\right)$. Thus, LOI measurements of the thin fibres were performed to obtain an empirical relationship between TS and LOI (Fig. 7).

After introducing the LOI value of $D$. floribunda and D. concinna fibre into Eq. 10, the results gave TS of 191.4 and $168.8 \mathrm{MPa}$, respectively. The respective deviations from the measured values are 2.8 and $14.7 \%$. The empirical relationship has thus been validated in the case of $D$. floribunda and D. concinna.

$$
\begin{aligned}
(\mathrm{LOI} \text { thin fibre }): \mathrm{TS}= & 341.81(\mathrm{LOI})^{3}-1821.9(\mathrm{LOI})^{2} \\
& +3224(\mathrm{LOI})-1724.1\left(R^{2}=0.93\right)
\end{aligned}
$$

Despite the fact that other factors such as the microfibril angle and the presence of several crystalline cellulose varieties (which have not been studied here) can influence the fibre TS, the results obtained clearly show a strong correlation between the IR indices and the TS. Furthermore, the newly proposed method derives from IR indices analyses already used by several researchers to determine the cellulose crystallinity. The IR indices analysis given by FT-IR test therefore makes it possible to estimate a fibre TS value, while keeping in mind that the comparisons must be limited to the interpretation of the cellulose crystallinity since any variation related to the fibre macroscopic property (lumens, fracture and default) will not be detected by the IR spectrum. Finally, as a third degree polynomial with non-zero coefficients, the propagation of errors in TS values given by Eqs. (7, 8, 9 and 10) are the same and equal to $14 \%$ since the relative error on each measurement of IR index is $2 \%$.

\section{Conclusion}

A new approach exploiting the results of a known method for determining the cellulose crystallinity has been proposed and successfully applied to predict the fibre tensile strength (TS) of different species within the same plant genus (seven Mascarenes Pandanus spp.). The TS prediction is based on the determination of the IR indices namely total crystallinity index $(\mathrm{TCl})$, lateral order index (LOI), and hydrogen bond index ( $\mathrm{HBI})$, which provide information on the cellulose crystallinity. The tensile test result of a relatively large number of samples (50 for every seven species) revealed strong inter- and intraspecies dispersion of the TS value. Thus, FT-IR measurements were performed to quickly and easily determine the TS values via these above-mentioned indices. Empirical equations linking the TS and these indices have been established and the correlation coefficient of TCl, $\mathrm{LOI}$ and $\mathrm{HBI}$ were found to be $95.8,98.3$ and $94.9 \%$, respectively. 
Among these three indices, $\mathrm{LOI}$ is the most reliable for estimating the fibre TS. The approach was also successfully validated (with high correlation coefficients) with fibres of two species of a different plant genus (Dracaena), thereby pointing to its wider applicability.

Funding This study was funded by the "Agence Universitaire de la Francophonie" (AUF).

\section{Compliance with ethical standards}

Conflict of interest We have no conflicts of interest to disclose.

\section{References}

1. Verma D, Senal I (2019) Natural fiber-reinforced polymer composites. In: biomass, biopolymer-based materials, and bioenergy. Elsevier, pp 103-122

2. Célino A, Fréour S, Jacquemin F, Casari P (2014) The hygroscopic behavior of plant fibers: a review. Front Chem. https:// doi.org/10.3389/fchem.2013.00043

3. Feigel B, Robles $H$, Nelson JW et al (2019) Assessment of mechanical property variation of as-processed bast fibers. Sustainability 11:2655. https://doi.org/10.3390/su11092655

4. Soatthiyanon N, Crosky A, Heitzmann M (2015) Comparison of experimental and calculated tensile properties of flax fibres. In: Proceedings of the 2nd international conference on performance-based and life-cycle structural engineering (PLSE 2015). School of Civil Engineering, The University of Queensland, Brisbane, QLD, Australia, pp 116-120

5. Wang G, Shi SQ, Wang J et al (2011) Tensile properties of four types of individual cellulosic fibers. Wood Fibre Sci 43:12

6. Alcock M, Ahmed S, DuCharme S, Ulven C (2018) Influence of stem diameter on fiber diameter and the mechanical properties of technical flax fibers from linseed flax. Fibers 6:10. https://doi. org/10.3390/fib6010010

7. Sathishkumar T, Navaneethakrishnan P, Shankar $\mathrm{S}$ et al (2013) Characterization of natural fiber and compositesa review. J Reinf Plast Compos 32:1457-1476. https://doi. org/10.1177/0731684413495322

8. Sena Neto AR, Araujo MAM, Souza FVD et al (2013) Characterization and comparative evaluation of thermal, structural, chemical, mechanical and morphological properties of six pineapple leaf fiber varieties for use in composites. Ind Crops Prod 43:529537. https://doi.org/10.1016/j.indcrop.2012.08.001

9. Carrillo F, Colom X, Suñol JJ, Saurina J (2004) Structural FTIR analysis and thermal characterisation of lyocell and viscosetype fibres. Eur Polym J 40:2229-2234. https://doi.org/10.1016/j. eurpolymj.2004.05.003

10. Ornaghi HL, Poletto M, Zattera AJ, Amico SC (2014) Correlation of the thermal stability and the decomposition kinetics of six different vegetal fibers. Cellulose 21:177-188. https://doi. org/10.1007/s10570-013-0094-1
11. Nelson ML, O'Connor RT (1964) Relation of certain infrared bands to cellulose crystallinity and crystal latticed type. Part I. Spectra of lattice types I, II, III and of amorphous cellulose. J Appl Polym Sci 8:1311-1324. https://doi.org/10.1002/app.1964.07008 0322

12. Khai DM, Nhan PD, Hoanh TD (2017) An investigation of the structural characteristics of modified cellulose from acacia pulp. Vietnam J Sci Technol 55:452. https://doi.org/10.15625 /2525-2518/55/4/9216

13. Rafidison BH, Ramasawmy H, Chummun J, Florens FBV (2018) Tree age, leaf maturity and exposure to sunlight influence tensile strength of fibres in Pandanus utilis. J Nat Fibers. https://doi. org/10.1080/15440478.2018.1558145

14. Kljun A, Benians TAS, Goubet $F$ et al (2011) Comparative analysis of crystallinity changes in Cellulose I polymers using ATR-FTIR, $X$-ray Diffraction, and Carbohydrate-Binding Module Probes. Biomacromol 12:4121-4126. https://doi.org/10.1021/bm201 $176 \mathrm{~m}$

15. Oh SY, Yoo DI, Shin Y et al (2005) Crystalline structure analysis of cellulose treated with sodium hydroxide and carbon dioxide by means of X-ray diffraction and FTIR spectroscopy. Carbohydr Res 340:2376-2391. https://doi.org/10.1016/j.carres.2005.08.007

16. Singh JK, Sharma RK, Ghosh P et al (2018) Imidazolium based ionic liquids: a promising green solvent for water hyacinth biomass deconstruction. Front Chem. https://doi.org/10.3389/ fchem.2018.00548

17. Široký J, Blackburn RS, Bechtold T et al (2010) Attenuated total reflectance Fourier-transform Infrared spectroscopy analysis of crystallinity changes in lyocell following continuous treatment with sodium hydroxide. Cellulose 17:103-115. https://doi. org/10.1007/s10570-009-9378-x

18. Poletto M, Ornaghi H, Zattera A (2014) Native cellulose: structure, characterization and thermal properties. Materials 7:61056119. https://doi.org/10.3390/ma7096105

19. Oh SY, Yoo DI, Shin Y, Seo G (2005) FTIR analysis of cellulose treated with sodium hydroxide and carbon dioxide. Carbohydr Res 340:417-428. https://doi.org/10.1016/j.carres.2004.11.027

20. Åkerholm $M$, Hinterstoisser B, Salmén L (2004) Characterization of the crystalline structure of cellulose using static and dynamic FT-IR spectroscopy. Carbohydr Res 339:569-578. https://doi. org/10.1016/j.carres.2003.11.012

21. Szymanska-Chargot M, Zdunek A (2013) Use of FT-IR Spectra and PCA to the Bulk characterization of cell wall residues of fruits and vegetables along a fraction process. Food Biophys 8:29-42. https://doi.org/10.1007/s11483-012-9279-7

22. Poletto M, Zattera AJ, Forte MMC, Santana RMC (2012) Thermal decomposition of wood: influence of wood components and cellulose crystallite size. Bioresour Technol 109:148-153. https ://doi.org/10.1016/j.biortech.2011.11.122

23. Fan M, Dai D, Huang B (2012) Fourier Transform Infrared Spectroscopy for natural fibres. In: Salih S (ed) Fourier transformmaterials analysis. InTech

Publisher's Note Springer Nature remains neutral with regard to jurisdictional claims in published maps and institutional affiliations. 